$\xi=$ 잘

\title{
Apexogenesis of traumatized maxillary right central incisor: Case report with 4years follow up
}

\author{
Mohammad Hammo DDS. ${ }^{1}$, Mazen Doumani DDS. MSc. ${ }^{2 *}$, Adnan Habib DDS. MSc. PhD. ${ }^{3}$ \\ 1 Private clinic, Amman, Jordan \\ ${ }^{2}$ Alfarabi Colleges of dentistry and nursing - Department of restorative dental sciences , Riyadh, Saudi Arabia \\ ${ }^{3}$ Buraydah Colleges. college of dentistry-Department of restorative dental sciences, buraydah, Saudi Arabia \\ *Corresponding author E-mail: Mazendom@hotmail.com
}

\begin{abstract}
The main goal of vital pulp therapy is to preserve and maintain pulpal health in teeth that have been exposed to caries, trauma, and restorative procedures. This type of endodontic treatment is very important in young permanent teeth that have not reached their complete length and exhibit thin-walled roots and wide open apices. The developments in knowledge of pulpal physiology and immunology, beside to newly introduced dental materials, have changed the treatment approaches for teeth with involved pulps. This report describes a case of a young patient in whom maxillary right central incisor suffered crown fractures because of a traumatic accident. Pulpotomy with MTA were performed in order to achieve apexogenesis and the tooth was restored with a glass ionomer cement and composite resin. The patient was reviewed over 4years.
\end{abstract}

Keywords: Apexogenesis, MTA, Open Apex, Pulpotomy.

\section{Introduction}

Traumatic injury is a main cause of pulpal damage in anterior teeth. Fractures in enamel, dentine and pulp have been named as complicated crown fractures (Andreasen JO \& Andreasen FM 1994). The degree of pulp involvement can vary from a pinpoint exposure to a total unroofing of the coronal pulp (Bakland LK 2002). The percentage of crown fractures with pulp exposure can reach to $13 \%$ of all dental traumatic injuries (Webber RT 1984). There are many ways to manage the complicated crown fractures like direct pulp capping, partial pulpotomy, cervical pulpotomy or pulpectomy (Nosrat A \& Asgary S 2010). The prognosis depending of these treatments is related to many factors such as the period between accident and dental office visit, degree of root development and size of pulp exposure (Olsburgh S et al. 2002, Andreasen FM et al. 1995). Root development takes 5 years or more after the tooth has erupted into the oral cavity (Keneth M. Hargreaves 2016). Injury to the young developing tooth results in a short root with a wide canal that can be either divergent or parallel and is associated with flared or cylindrical root apex. American Association of Endodontists (AAE) defined apexogenesis as a physiologic root end development and formation. The recent term is"vital pulp therapy" and according to Walton and Torabinejad is defined as the treatment of a vital pulp in an immature tooth to permit continued dentin formation and apical closure (Pitt Ford TR \& Shabahang S 2002). The goals of apexogenesis are: allowing continued development of root length, maintain pulp vitality, allow continued deposition of dentin, promoting root end closure, and generating Dentine Bridge at the site of pulpotomy (Glickman GN et al. 2009). Studies showed that MTA produces a thicker dentinal bridge, less inflammation, less hyperemia, and less pulpal necrosis compared with calcium hydroxide (Asgary S et al. 2008, Patel R \& Cohenca N 2006). The purpose of this case report is to describe a case in which vital pulp therapy for exposed maxillary right central incisor pulp was performed and the tooth was clinically and radiographically periodically evaluated.

\section{Case report}

A 7-year-old girl (with a noncontributory medical history) brought to our clinic with a history of prior impact trauma 8 hours before her initial visit. The patient's chief complaint was sensitivity to cold beverage and pain in chewing. Clinical examination showed a complicated crown fracture with pulpal exposure on the right maxillary central incisor. The tooth was sensitive in percussion test but not in palpation. Radiographic examination showed that fractured tooth had immature apex and approximately $11 \mathrm{~mm}$ in length (Fig. 1A). Under local anesthesia with 2\% lidocaine and 1:100,000 epinephrine (Lignospan® standard, Canada) and rubber dam isolation, access cavity was prepared with a diamond fissure bur followed by cervical pulpotomy by using a long shank round diamond bur with high speed and copious water spray to prevent heat damage to subjacent pulp. The area was rinsed with normal saline solution. Hemostasis was achieved by gentle placement of a moistened sterile cotton pellet over the amputated pulp. Following the company instructions, ProRoot white MTA (Dentsply Tulsa Dental Specialties, Tulsa) cement, powder and liquid were mixed to achieve a creamy consistency. 3-mmthick layer of MTA was placed over the exposed pulpal wound by using an amalgam carrier (Fig. 2A) and was gently adapted to the 
dentinal walls of the access cavity with a dry cotton pellet. A moistened cotton pellet was placed gently over MTA, and then the tooth was temporarily filled with Cavite. After one day temporary restoration was removed to assure the setting of the capping material, and the tooth was restored by using tooth was restored by using acid-etch technique and the composite material (3M Espe resin Z350). Patient was recalled 12(Fig. 3A), 24(Fig. 4A), 39 (Fig. 5A) and 49months (Fig. 6A) after the treatment for follow up in spite of that the patient should be recalled at a minimum of 3-month intervals after apexogenesis therapy in order to determine the vitality of the pulp and the extent of apical maturation. The tooth was functional and no symptomatic, with no evident clinical signs. Root development, formation of root apex, and formation of a calcified bridge beneath MTA cement were radiographically evident at the follow up sessions. The (Fig. B) shows the root length increasing of the treated tooth during the whole period of following up.
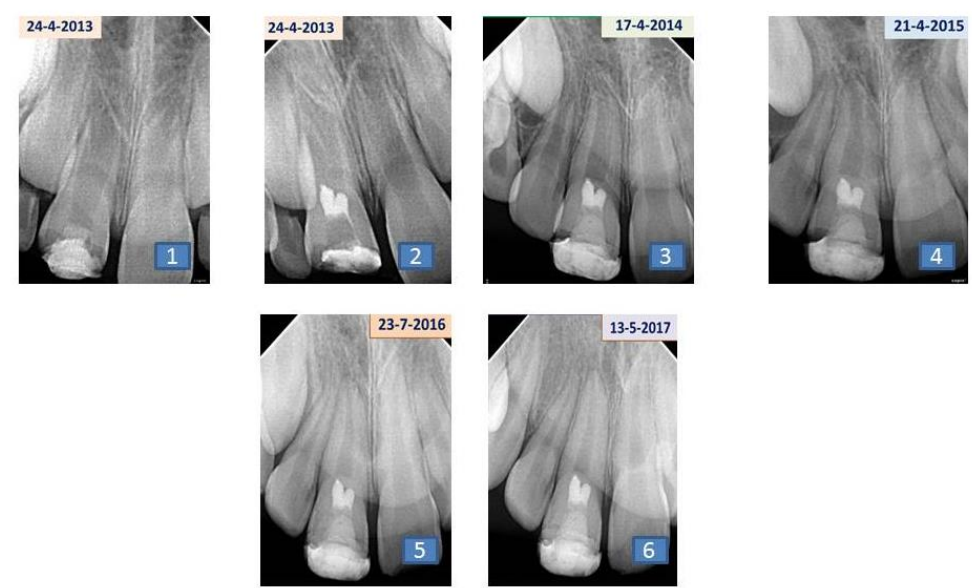

Fig. 1: (1-6): The Root Development During the Period of Follow Up Visits.

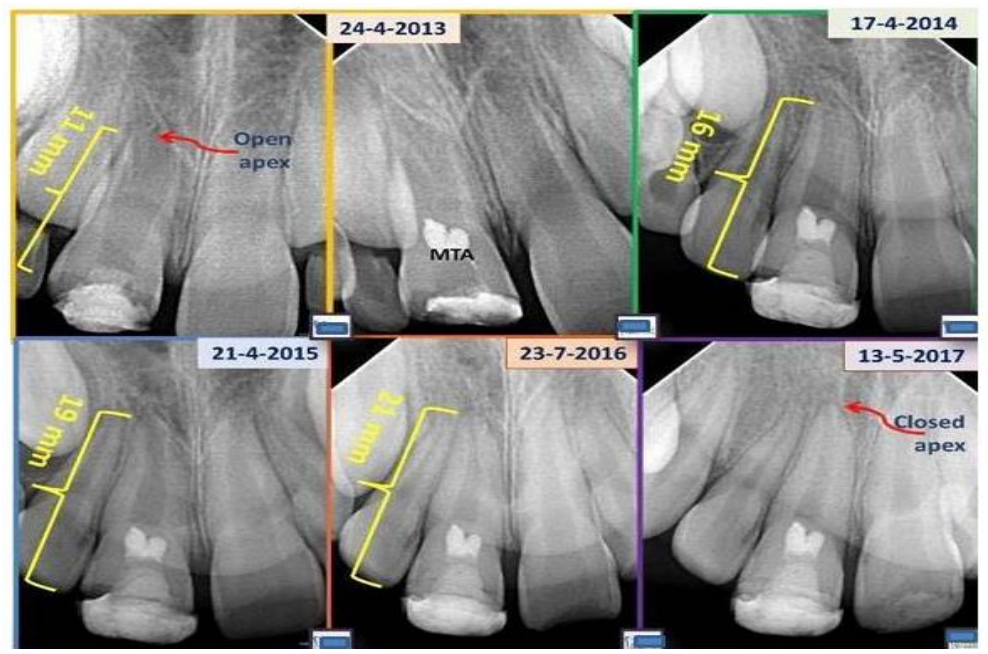

Fig. 2: The Root Development (Approximate Lengths during the Period of Follow up Visits).

\section{Discussion}

Vital pulp therapy is a reasonable treatment for teeth with open apices and vital pulp .It has an important role in young permanent teeth to preserve the pulp vitality (Souza RA et al. 2007). If this treatment is performed successfully, the intact pulp will provide apical development and promote deposition and maturation of the dentin on internal walls of root canal system (Belobrov I et al. 2008). Crown fractures usually lead to pulp contamination by oral microorganisms. The partial Pulpotomy is the treatment of choice after pulpal exposure of immature teeth with open apices (Cvek M 1978). In the present case, however, considering the large fracture of crown leading to large pulpal exposure, we performed cervical pulpotomy (Kontham UR et al. 2005). Sealing ability, alkalinity, and biocompatibility are properties of pulp capping materials (like MTA) which may explain the formation of dentinal bridge beneath this materials (Ford TR et al. 1996). MTA cement has comparable biocompatibility when used as pulp capping materials (Asgary S et al. 2008). The quality of reactionary dentin and bridge formation under MTA likes normal dentin (Andelin WE, et al 2003). The coronal seal after pulp capping is an important step to prevent treatment failure (Barthel CR et al. 2000, Cox CF et al. 1987). Composite resin is the material of choice to cover capping material, beside to the reasonable esthetic particularly in anterior teeth (Olsburgh S et al. 2002). 1 day after the pulp capping with MTA cement, the tooth in this case report was restored by using acid-etch composite. Clinical signs and symptoms and radiographic signs of pulpal and periapical pathologic changes are the major means of indicating the state of the pulp so we did not neglect the important role of follow up step. In conclusion, clinical application of MTA cement as a pulp capping material for apexogenesis can be a suitable treatment choice. This case report highlight the need for regular follow up following any procedure in young permanent dentition.

\section{References}

[1] Andreasen JO, Andreasen FM. Textbook and colour atlas of traumatic injuries to the teeth. 3rd ed. St. Louis, MO: Mosby; 1994. 
[2] Bakland LK. Endodontic considerations in dental trauma. In: Ingle JI, Bakland LK, eds. Endodontics. 5th ed. London: BC Decker Inc.2002: 795844.

[3] Webber RT. Apexogenesis versus apexification. Dent Clin North Am 1984; 28: 669-97.

[4] Nosrat A, Asgary S. Apexogenesis treatment with new endodontic cement: a case report. J Endod 2010; 36:912-4. https://doi.org/10.1016/j.joen.2009.11.025.

[5] Olsburgh S, Jacoby T, Krejci I. Crown fractures in the permanent dentition: pulpal and restorative considerations. Dent Traumatol 2002; 18:10315. https://doi.org/10.1034/j.1600-9657.2002.00004.x.

[6] Andreasen FM, Noren JG, Andreasen JO, Engelhardtsen S, Lindh-Stromberg U. Long-term survival of fragment bonding in the treatment of fractured crowns: a multicenter clinical study. Quintessence Int 1995; 26: 669-81.

[7] Keneth M. Hargreaves, Louis H. Berman. Cohen's Pathways of the pulp. $11^{\text {th }}$ ed. Elsevier; $2016 ; 849$.

[8] Pitt Ford TR, Shabahang S. Management of incompletely formed roots. In: Walton RE, Torabinejad M, editors. Principles and Practice of Endodontics. 3rd ed. Philadelphia: W.B. Saunders Co. 2002; 388-404.

[9] Glickman GN, Bakland LK, Fouad AF, Hargreaves KM, Schwatrz SA, et al. Diagnostic terminology, report of an online survey. J Endod 2009; 35(12): 1625-1633. https://doi.org/10.1016/j.joen.2009.09.034.

[10] Asgary S, Eghbal MJ, Parirokh M, Ghanavati F, Rahimi H. A comparative study of histologic response to different pulp capping materials and a novel endodontic cement. Oral Surg Oral Med Oral Pathol Oral Radiol Endod 2008; 106:609-14. https://doi.org/10.1016/j.tripleo.2008.06.006.

[11] Patel R, Cohenca N. Maturogenesis of a curiously exposed immature permanent tooth using MTA for direct pulp capping: a case report. Dent Traumatol 2006; 22:328-33. https://doi.org/10.1111/j.1600-9657.2006.00471.x.

[12] Souza RA, Gomes SC, Dantas Jda C, Silva-Sousa YT, Pecora JD. Importance of the diagnosis in the pulpotomy of immature permanent teeth. Braz Dent J 2007; 18:244-7. https://doi.org/10.1590/S0103-64402007000300013.

[13] Belobrov I, Weis MV, Parashos P. Conservative treatment of a cervical horizontal root fracture and a complicated crown fracture: a case report. Aust Dent J 2008; 53:260-4. https://doi.org/10.1111/j.1834-7819.2008.00058.x.

[14] Cvek M. A clinical report on partial pulpotomy and capping with calcium hydroxide in permanent incisors with complicated crown fracture. J Endod 1978; 4:232-7. https://doi.org/10.1016/S0099-2399(78)80153-8.

[15] Kontham UR, Tiku AM, Damle SG, Kalaskar RR. Apexogenesis of a symptomatic mandibular first permanent molar with calcium hydroxide pulpotomy. Quintessence Int 2005; 36:653-7.

[16] Ford TR, Torabinejad M, Abedi HR, Bakland LK, Kariyawasam SP. Using mineral trioxide as a pulp-capping material. J Am Dent Assoc 1996; 127:1491-4. https://doi.org/10.14219/jada.archive.1996.0058.

[17] Andelin WE, Shabahang S, Wright K, Torabinejad M. Identification of hard tissue after experimental pulp capping using dentin sialoprotein (DSP) as a marker. J Endod 2003; 10:646-50 https://doi.org/10.1097/00004770-200310000-00008.

[18] Barthel CR, Rozenkranz B, Leuenberg A, Roulet JF. Pulp capping of carious exposures: treatment outcome after 5 and 10 years: a retrospective study. J Endod 2000; 26:525-8. https://doi.org/10.1097/00004770-200009000-00010.

[19] Cox CF, Keall CL, Keall HJ, Ostro E, Bergenholts G. Biocompatibility of surface-sealed dental materials against exposed pulps. J Prosthet Dent 1987; 57:1-8. https://doi.org/10.1016/0022-3913(87)90104-1. 